\title{
THE MEANING OF SIGNS IN “BREAST CANCER SURVIVOR'S FIRST HAIRCUT” ULTA BEAUTY ADVERTISEMENT
}

\author{
Ni Made Yugi Astari \\ Mahasaraswati Denpasar University \\ yugiastari9@gmail.com \\ Desak Putu Eka Pratiwi \\ Mahasaraswati Denpasar University \\ desak.eka.pratiwi@gmail.com \\ I Dewa Ayu Devi Maharani Santika \\ Mahasaraswati Denpasar University \\ devimaharani17@gmail.com
}

\begin{abstract}
The meaning of signs in advertisements is very important to make it easier for the audience to understand the content and purpose of the advertisement. This study aims to discover the meaning of verbal and nonverbal signs and discover the meaning of verbal and nonverbal signs found in the "Breast Cancer Survivor's First Haircut" Ulta Beauty advertisement. Verbal signs are about text, either words or sentences while nonverbal signs are about pictures. The data were taken from Ulta Beauty Company YouTube account. The data were collected by observation method. In the research there are several theories used to analyze the data, semiotic theory by Saussure (1983) was used in analyzing verbal and visual signs in advertisement. The second is the theory of meaning proposed by Barthes (1964) to analyze the meaning of signs which consist of two layers, denotation and connotation. The last is the theory of Wierzbicka (1996) to analyze the meaning of colors. The finding shows that both verbal and visual signs have denotative and connotative meaning. Verbal and visual signs are both supporting each other to emphasize the message of the advertisement and to convince people to do particular actions
\end{abstract}

Keywords: advertisement; meaning; verbal signs; visual signs

\section{INTRODUCTION}

Advertising is a means used by a company to market a product. Companies are very dependent on advertising because without advertising the company as producers and distributors will not be able to sell their products. Apart from marketing their products, companies engaged in public services also produce advertisements for the benefit of education, community service, provide information and offer services. Advertisements are news orders to encourage, persuade the general public to be interested in the goods and services offered. Generally, advertisements are delivered through mass media, such as television, radio, newspapers and the internet. Advertisement contains messages to try to persuade consumers to buy products or use services offered and understand the information presented. Good and effective advertising must be able to attract attention, make consumers interested so that consumers will have the desire to buy the product or use the service. In advertising that aims to attract the attention of consumers or audiences, the use of signs is needed to beautify advertisement, both in the form of print ads and commercial video ads. A sign is a symbol of an object that functions as a means of presenting something that looks abstract.

Signs in advertisement include gestures, colors, images, facial expressions, art, posture, graphics, company logos, and illustrations shown in advertisement. Colors play important 
role in advertisement as one of the elements of visual signs. Wierzbickaproposed that 'color' is not a universal human concept, but it is correlated to the seeing which considered universal, because color is definable only via seeing. The color conceptualization is different in different culture although there are also some striking similarities (Wierzbicka, 1996: 287). Signs in advertisement have a meaning related to the advertising topic. Such as the verbal and visual signs of a short film of Breast Cancer Survivor's First Haircut by Ulta Beauty which documented the first haircut treatment for postbreast cancer patients. Ulta Beauty is the largest beauty retailer in the United States covering cosmetics, skin care products, hair care products, fragrances, and salon services. Ulta Beauty was founded in 1990 by Dick George, Terry Hanson, Parker Rosen. Ulta Beauty Company has a charity program called The Ulta Beauty Charitable Foundation (UBCF) which aims to support the education, welfare of women and their families by joining the Breast Cancer Research Foundation since 2009 and raising funds to help breast cancer research. Research Foundation is a non-profit organization that committed to achieving breast cancer prevention. This advertisement serves as a service marketing advertisement as well as a motivational movement.

This advertisement video contains several photos that have a positive message for society and for breast cancer fighters. Apart from being a motivation, this advertisement also aims to introduce the service and for a fundraising program for breast cancer research. This research aims to analyze the meaning of verbal and visual signs such as sentences, symbols, gestures, colors, and facial expressions. According to Chandler (2001: 27) verbal sign is something that deals with text and words. Meanwhile, visual signs are defined as images or gestures that are not spoken, but still convey meaning through visible illustration media. It combines art, symbols, illustrations, images, colors, graphics, gestures, facial expressions, postures, which are shown in advertisements which are very interesting to analyze.

\section{METHOD}

The data of this study were taken from the short film Ulta Beauty entitled "The First
Haircut for Breast Cancer Survivors". This advertisement was first uploaded via YouTube on October 10, 2015 with two minutes, two seconds duration. The narrative in the advertisement was written by cancer survivor Tracey De Soto, who was initially full of despair. In the video Tracey De Soto shows a picture of her condition before and after suffering from breast cancer, how the condition of her hair due to breast cancer has made her lose her self-confidence. This study used observation methods in collecting the data. Meanwhile a qualitative method was used to analyze the meaning of verbal and visual signs found in Breast Cancer Survivor's First Haircut Ulta Beauty advertisement by using the theory of semiotics proposed by Saussure (Saussure, 1983), supported by other relevant theories from Barthes (Barthes, 1964) and Wierzbicka (Wierzbicka, 1996b).

\section{DISCUSSION}

This study used an advertisement of Ulta Beauty entitled "Breast Cancer Survivor's First Haircut" which contains several photos and moving pictures. The data were analyzed by using semiotic approach. Semiotics has been defined as "the science of the life of signs in society" by Saussure (1974). Semiotics offers the promise of a systematic, comprehensive and coherent study of communications phenomena as a whole, not just instances of it. Semiology aims to take in any system of signs, whatever their substance and limits; images, gestures, musical sounds, objects, and the complex associations of all these, which form the content of ritual, convention or public entertainment (Barthes, 1964).

In this study the researcher found verbal and visual signs consisting of sentence, human, facial expression, hair cutting equipment, photo, and quotes paper. The sign is the whole that results from the association of the signifier with the signified (Saussure, 1983). Both verbal and visual signs are very crucial in advertisement. Dyer implies that in order to understand the feature of human subjects we also need to delineate the principle nonverbal means by which people communicate (Dyer, 1982). It is very interesting to analyze the meaning of verbal and visual signs which basically have conceptual and connotative 
meaning. Conceptual meaning sometimes called denotative or cognitive meaning. It is considered as the central factor in linguistic communication. Meanwhile connotative meaning is the communication value an expression has by virtue of what it refers to over and above it is purely conceptual content (Leech, 1974). The analysis of verbal and visual signs will be presented as follows.

Data 1

Verbal signs : "I'll never forget this feeling" Visual signs : A picture of woman smiling

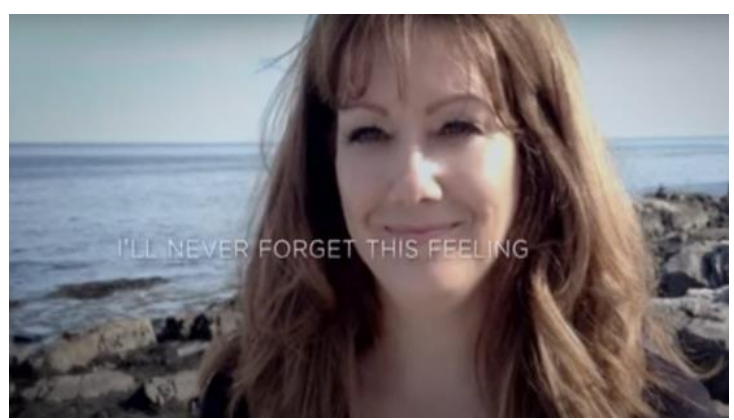

The above statement contains connotative meaning, because the word "feeling" in the statement above is not just an emotional feeling but also means the perception of the event or reaction in the situation she is experiencing. Based on her life story as a breast cancer survivor, what she felt when she became a breast cancer patient was not only sad, but the reaction she got from her was a loss of selfconfidence, a rather shocking reaction by living a life that is a little different from other healthy people, like life with limited body movement, due to loss of movement function in several organs, feel weak and need a lot of rest.

The image of a smiling woman in this advertisement contains connotative meaning. The woman in the picture above only expresses her feelings with a smile, her smile does not only mean happiness, but her smile also means that she feels grateful to be able to go through her struggle against breast cancer. A smile also means covering up the pain, sadness, disappointment, hopelessness she felt while fighting breast cancer. Cancer sufferers don't want to look weak and want to always look strong to loved ones and passion for other cancer fighters. Her recovery and ability to undergo the process of breast cancer treatment made her unable to forget the joys and sorrows of her struggle to restore her health.

Data 2

Verbal signs : "This disease is going to take away my beauty and don't try to convince me that there is a silver lining at the end of this journey, because when you really think about it life is unfair"

Visual signs : A woman and a picture of a hair lost on hand
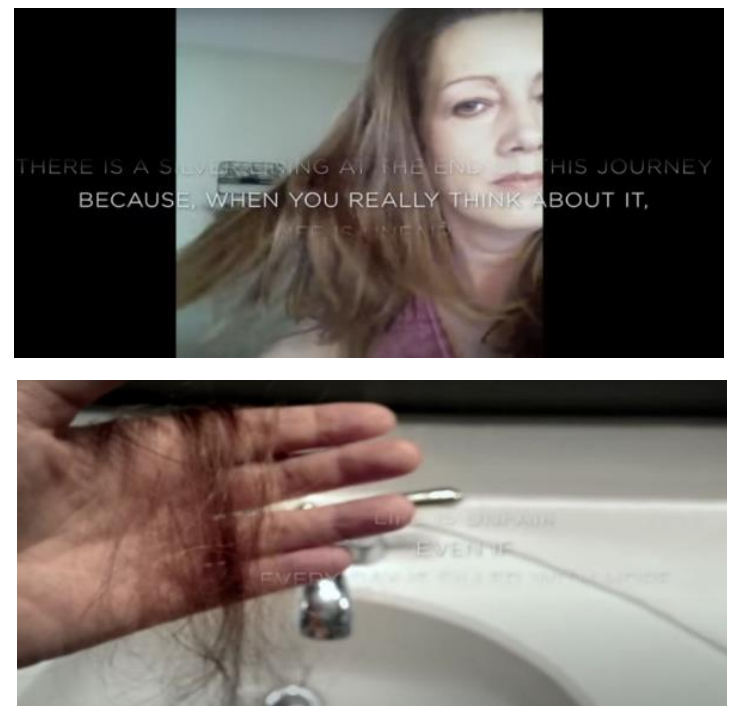

The above statement has a connotative meaning. First, from the sentence "this disease will take away my beauty", her breast cancer not only caused the loss of important organs in her body but also caused her beauty to decrease because during cancer treatment such as chemotherapy it had an impact on hair loss. Hair is a beauty icon of a woman's beauty. Hair shape and hair beauty are the main and most important things supporting the beauty of every woman.

Second, there is the word "Silver Lining" which is part of the adage "every cloud has a silver lining" which means that every difficult and sad situation will have some good behind it. The word "silver lining" means something good from something unpleasant. As a cancer patient who has experienced various adversities and already feels hopeless, he doesn't want to hear grandiose things or other good possibilities. They will increasingly feel life is not fair 
The visual sign that appears in the image above is hair loss in breast cancer sufferers. These scenes contain denotative meaning because hair loss is one of the most visible effects for cancer sufferers during the treatment process such as chemotherapy. The rate of hair loss depends on the type and dose of chemotherapy drugs. Some patients will only experience thinning hair, while others will experience complete loss. Hair loss conditions can be experienced by both male and female patients, both children and adults.

For a woman, hair loss causes her to lose her self-confidence and feel that she doesn't look beautiful. Apart from losing her breasts which are an important asset in her body, she also lost her beautiful hair, in which a woman is synonymous with long and beautiful hair. Losing hair due to baldness seemed to dim their beautiful side as women and losing breasts was like losing part of their life.

Data 3

Verbal signs : "It's all beyond my control and you will never hear me say I am still beautiful"

Visual signs : Quotes paper on the mirror

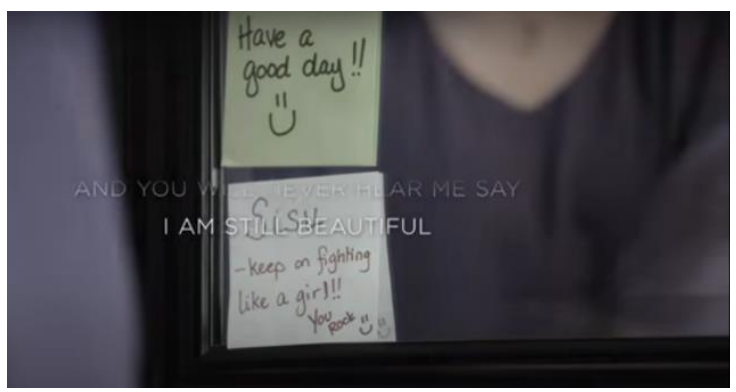

The above statement contains denotative meaning. Explain that all negative feelings such as hopelessness, loss of confidence, fear and worry are difficult for her to control. All of that is beyond her control. Cancer sufferers generally experience the same situations and circumstances, such as feelings of hopelessness, because where she feels nothing can be done, gives up on restoring her health and feels as if she doesn't have the energy to start her normal daily activities of life. Her feelings of negativity and despair, she wanted to make sure people would never hear her say she was beautiful no matter what.
The visual sign in the above scene is the quote paper in the mirror. This scene contains connotative meaning because indoor objects are not only used to beautify the room, but in addition to photos and paintings there is also a quote paper containing motivational sentences that serve as a reminder to always act according to the contents of the quote for the owner or for other people as well.

Apart from the walls of the house, some people place them in places they often pass and use, such as mirrors. In the video, placing a paper quote on the mirror is not only a decoration, but also aims to remind her to always be excited and keep fighting when they look at the mirror. When breast cancer patients see the state of their bodies in the mirror, many of them will feel sad, but looking at the motivational words in the mirror can help them feel strong and stay energized. Her enthusiasm can also help speed up their healing process.

Data 4

Verbal signs : "My positivity will prevail over this, I can beat it, I no longer think the fear is too powerful because I am strong enough and it is not true that my courage won't last"

Visual signs : A picture of bald woman with dark background and a picture of a woman with her baby
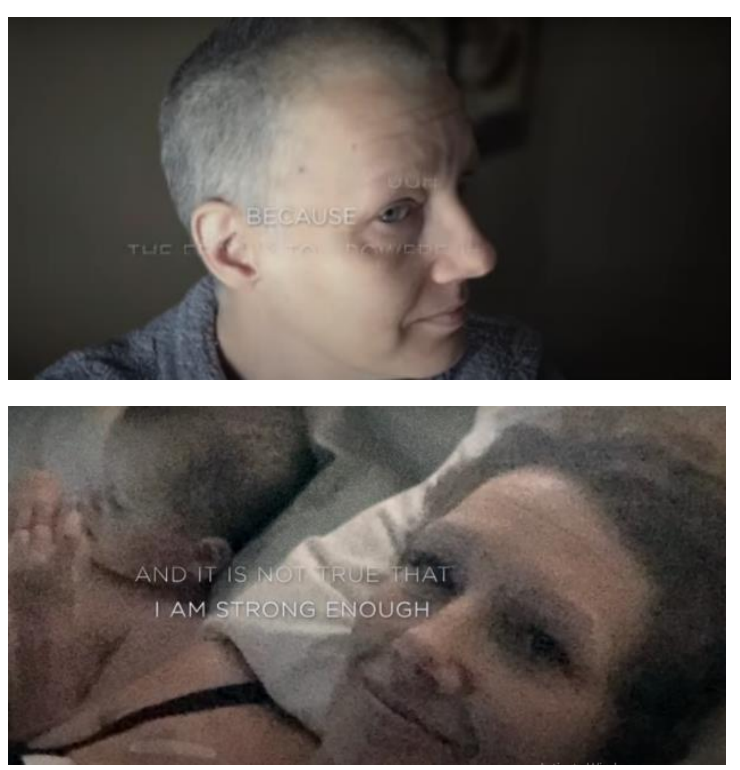
The above statement makes it clear that he is no longer thinking about her fear, she feels strong enough to fight her illness and is still struggling. This has a connotative meaning, because the word "POSITIVITY" here means that her positive thoughts will overcome all negative thoughts from her fear. Cancer patients who think positive will recover faster from their disease, because patients who think positive tend to be more diligent in undergoing treatment and positive thinking can strengthen their enthusiasm for a better life.

The visual sign of the above scene is showing a bald woman with breast cancer. These scenes contain denotative and connotative meaning. Denotative meaning in this scene is cancer sufferers will experience hair loss as a side effect of troublesome treatments such as chemotherapy. Hair loss due to chemotherapy depends on the type of drug and the level of the drug used.

Meanwhile connotative meanings in this scene are being bald can be challenging for cancer sufferers to reconsider their sense of identity and femininity. Hair loss to baldness after treatment and cancer has disappeared is a beautiful reality because it indicates they have fought and won. Being bald can also teach them to love themselves more. Hair or no hair, they are still fortunate to be here to celebrate God's grace in their lives.

The color background also contains connotative meaning. According to Wierzbicka (1996: 303) white and black are colors that are closely related to light and dark. The color white is associated with purity, goodness, while black is associated with strength, mystery, evil and death. In the above scene, the dark color in the background is likened to the bad situation she is in due to breast cancer which took away some of her happiness, and the light color in the middle is like a change to a better situation after her sacrifice and struggled to recover despite the loss of her beautiful breasts and hair.

A picture of a woman smiling with her baby contains connotative meaning, because related to the statement of verbal signs, a woman smiling with her baby means a baby as a source of strength for her to continue fighting breast cancer. The smile of this woman shows that she is strong against her disease because she has a source of her strength, namely her baby.
Smiling also means covering the pain as well as a reaction to maintain her confidence in the process leading to her awakening.

Data 5

Verbal signs : "Every day is filled with hope even if life is unfair because when you really think about it there is a silver lining at the end of this journey and don't try to convince me that this disease is going to take away my beauty"

Visual signs : Hair stylist cuts hair and women with short hair
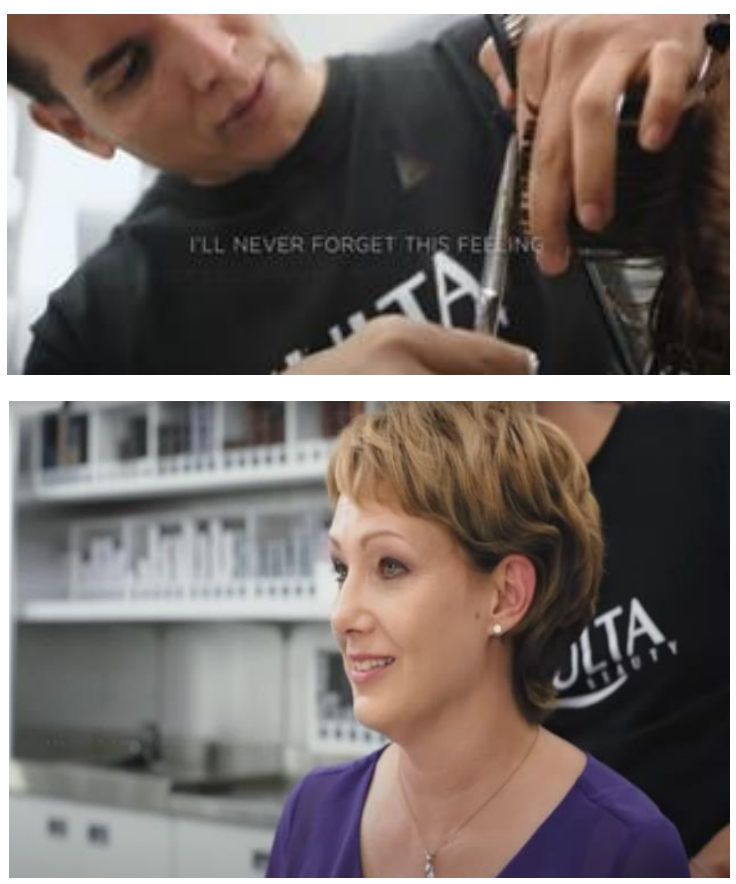

The above statement has a connotative meaning. This woman has hopes to face her illness and gives advice to others who may experience the same thing. The word "Silver Lining" which is part of the adage "every cloud has a silver lining" means that every difficult and sad situation sometimes also has an advantageous aspect. The word "silver lining" means something good from something unpleasant. Cancer sufferers always fill their minds and lives with good hopes from their struggles.

Breast cancer will damage one of the important organs in a woman's body and cancer treatment has an impact on damage to nails, skin, hair and metabolism. But a woman is still 
a woman, someone who is beautiful inside and out, women are destined to be beautiful regardless of the shape of their hair, what the color of their skin is.

The visual sign in above scene is a hair stylist who is cutting hair using hair cutting tools. This scene contains denotative meaning. According to the scene shown in the advertisement, the hair stylist from Ulta Beauty cuts the hair of a cancer patient who is not getting enough treatment after going through healing treatment such as chemotherapy. Chemotherapy makes body hair more easily damaged and untidy. Cutting her short hair did not reduce her joy after going through her struggles. Having healthy and neat hair again is the dream of all cancer sufferers.

\section{CONCLUSION}

After conducting the analysis, the authors found several points that can be concluded. In this advertisement, verbal and visual signs have meaning based on Barthes' theory of meaning which consists of denotative and connotative meanings. Based on the analysis, the meaning that is mostly found is connotative meaning. The connotative meaning used in several signs in this advertisement aims to attract the attention of the audience and persuade the audience to be interested in knowing the real content and purpose of the video, while several other signs have denotative meanings. The denotative meaning contains a literal meaning that makes it easier for the audience to understand what is being conveyed in the video. Connotative and denotative meanings are analyzed from several verbal signs and visual signs. Verbal signs in the form of sentences, and visual signs in the form of photos, facial expressions, and colors.

\section{REFERENCES}

Barthes, R. (1964). Elements of Semiology. Hill and Wang.

Dyer, G. (1982). Adertvising as Communication. Routledge.

Leech, G. (1974). Semantics: The Study of Meaning, Second Edition. Penguin Book.

Saussure, F. de. (1983). Course in General Linguistics (Bally, C. \& Sechehaye, A.). McGraw-Hill Book Company.

Wierzbicka, A. (1996a). Semantics: primes and universals. Oxford University Press.

Wierzbicka, A. (1996b). Semantics Primes and Universals. Oxford University Press. 